\title{
Research Paper: Prevalence and Risk Factors of Low Back Pain Among the Office Workers of King Edward Medical University Lahore, Pakistan
}

\author{
Syed Asadullah Arslan ${ }^{1}$, Mohammad Reza Hadian ${ }^{12^{*}}$, Gholamreza Olyaei ${ }^{1}$, Hussein Bagheri ${ }^{1}$, Mir Saeed Yekaninejad $^{2}$, Sahar Ijaz $^{3}$, Ali Arab
} Kheradmand ${ }^{4}$

1. Department of Physiotherapy, School of Rehabilitation, International Campus, Tehran University of Medical Sciences, Tehran, Iran.

2. Brain and Spinal Injury Repair Research Center (BASIR), Tehran University of Medical Sciences, Tehran, Iran.

3. Department of Anatomy, School of Medicine, International Campus, Tehran University of Medical Sciences, Tehran, Iran.

4. Institute of Cancer, Imam Khomeini Hospital, Tehran, Iran.

Citation: Arslan SA, Hadian MR, Olyaei Gh, Bagheri H, Yekaninejad MS, Ijaz S, et al. Prevalence and Risk Factors of Low Back Pain Among the Office Workers of King Edward Medical University Lahore, Pakistan. Physical Treatments. 2016; 6(3):161-168. https://doi.org/10.18869/nrip.ptj.6.3.161

https://doi.org/10.18869/nrip.ptj.6.3.161

Article info:

Received: 01 May 2016

Accepted: 30 Jul. 2016

Keywords:

Low back pain,

Prevalence, Risk factors

\section{A B S T RA C T}

Purpose: In the present era, Low Back Pain (LBP) is a destructive health problem. It affects many people and accounts for huge economic loss. Office workers have a unique lifestyle while working in sedentary position with poor body posture for long periods of time. The musculoskeletal problems can result in inconvenience or pain with bad impact on the quality of life.

Methods: This cross-sectional study was done to find the prevalence and risk factors of LBP among the office workers of King Edward Medical University (KEMU), Lahore, Pakistan. After taking the ethical approval from Institutional Review Board (IRB), KEMU, Lahore, a sample size of 300 office workers was calculated by using proportion formula of sample size estimation with $5 \%$ margin of error from KEMU with effect from Jan 2015 to Sep 2015. Participants aged between 18 and 60 years with at least 1 year work experience completed the validated questionnaires.

Results: Results showed that point and lifetime prevalence of LBP among office workers of KEMU, Lahore, Pakistan was $29.20 \%$ and $69.20 \%$, respectively. LBP prevalence rose with the increase in age, work experience, low education, low physical activity, sleep disturbance, smoking habit, more sitting and standing time, computer use, and low job satisfaction.

Conclusion: We concluded that different individual, ergonomic, and psychosocial factors were associated with LBP. Because of high prevalence of LBP among office workers of this university, better ergonomic facilities and awareness about sitting posture, regular exercise, good sleep, and psychological support to the workers were recommended to decrease the effects of predisposing risk factors of LBP.

\section{* Corresponding Author:}

Mohammad Reza Hadian, $P h D$

Address: Brain and Spinal Injury Repair Research Center (BASIR), Tehran University of Medical Sciences, Tehran, Iran.

Phone: +98 (21) 77533939

E-mail: hadianrs@sina.tums.ac.ir 


\section{Introduction}

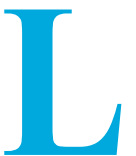

ow back pain (LBP) is a major health problem and two third of the adult population suffer from LBP at some time in their lives and approximately $12 \%$ to $44 \%$ of people have LBP at any given time [1] in their lives with an estimated point prevalence of 33\% among office workers [2]. Because of high variation in clinical characteristics, lack of consensus over diagnostic criteria or clinical classification, wide variation in course and prognosis, and limited success in finding effective treatments, LBP manifests itself a big challenge for clinicians and researchers. However, new research has generated a wealth of evidence on the epidemiology, prognosis, and treatment of back pain [3].

Comparing the prevalence of LBP between populations has become more challenging over time due to considerable methodological heterogeneity across studies and difficulties in obtaining true population estimates. Instead of incidence, remission and duration, prevalence of LBP has been found more in the literature [4].

Office workers share numerous behavioral patterns while working in a static sitting position for long periods of time using a small number of muscles of their arms, wrists and hands; and are liable to adopt poor body posture. Such working conditions generate musculoskeletal disorders that can lead to uneasiness or pain with a bad impact on the quality of life [5]. "LBP among office workers" is an attractive topic among researchers because of its high prevalence in this particular group. In a survey conducted in the Dutch working groups, including office workers, musculoskeletal disorders, especially LBP were associated with long duration sickness absence [6].

A number of epidemiological studies have been conducted to find out the emergence and associated risk factors of LBP among office workers [7-12]. Some studies were also done regarding work related musculoskeletal problems in Iran that showed high prevalence of the musculoskeletal symptoms in different work settings such as automobile factories [13], rubber factories [14], carpet mending operations [15], and health care settings [16].

LBP among office workers was prevalent but in Pakistan no such research has done before to know about the problem among office workers. The main goal of this study was to find out the prevalence and risk factors of LBP among the office workers of King Edward Medical University (KEMU) Lahore, Pakistan.

\section{Materials and Methods}

After the ethical approval from Institutional Review Board (IRB) of KEMU, Lahore, a sample size of 300 office workers was calculated. By using the proportion formula of sample size estimation with 5\% margin of error. Participants aged between 18 and 60 years with at least 1 year work experience completed the validated questionnaires.

The present study was done from Jan 2015 to Sep 2015 by randomly selecting a sample of office workers from different administration offices, hospitals and educational departments of KEMU, Lahore, Pakistan. After screening process, 50 questionnaires were excluded based on exclusion criteria. For further analytic process, 250 questionnaires were considered valid. Office workers with any recent surgery, trauma, pregnancy, fracture, rheumatic and systemic disease, congenital problem were excluded from the study. Questionnaires were distributed among those office workers who were willing to participate in the research. The study purpose was explained to them with potential future benefits and if needed with further clarification. The office workers filled the questionnaires during their free time and then handed them back to the researcher.

A point prevalent case refers to an individual who suffers from LBP at the time of the survey and lifetime prevalent case refers to a person who has felt at least one LBP episode during his/her lifetime. After examining the different valid and reliable questionnaires that had already been published in the scientific literature [17, 18], a self-administered questionnaire was constructed in Urdu. Forward-Backward translation was made and experts assessed the questionnaire for its validity. Total number of items in this questionnaire were 21 , which were examined and considered appropriate regarding construct and content validity. Questions about the individual characteristics included gender, age, weight, marital status, height, education level, smoking, exercise, number of exercise sessions in a week and sleep disturbance. Questions regarding work ergonomics consisted of work experience, hours spent on sitting, hours spent on computer use, standing time, frequently bending during work, presence of forward bent body position more than 2 hours while sitting, computer screen distance from the body and characteristics of chair (back support, adjustable back support).

After feeding the data in SPSS 21, we examined the frequency distributions of responses, cross-tabulations of individual, work ergonomic, and psychosocial factors in relation to reported point prevalence and lifetime prevalence 
of LBP. Group differences were further studied by the Chisquare test and significant $(\mathrm{P}<0.05)$ values were saved.

Multivariate and bivariate logistic regressions were analyzed to study the effect of several dependent variables on the outcome factors. The associations among individual, work ergonomic, psychosocial risk factors, and LBP prevalence were expressed by adjusted OR with 95\% confidence interval. Only significant determinants were included in the prediction of point prevalence and lifetime prevalence of LBP (outcome factors) from individual, ergonomic, and psychosocial risk factors $(\mathrm{P}<0.05)$.

\section{Results}

Minimum age of the participants was 24 years and maximum age was 60 years with standard deviation of 9.54 years. Minimum body mass index was 18.73 and maximum BMI was $38.06 \mathrm{~kg} / \mathrm{m}^{2}$ with standard deviation of $3.89 \mathrm{~kg} / \mathrm{m}^{2}$. Data regarding demographic, personal, work related characteristics as well as point and lifetime prevalence of LBP are shown in Table 1.

Point and lifetime prevalence of LBP among office workers of KEMU, Lahore, Pakistan were $29.20 \%$ and $69.20 \%$, respectively. Point as well as lifetime prevalence of LBP was high among female workers as compared to male workers, but there was no association between gender and low back pain. Married office workers showed high point and lifetime prevalence of LBP with respect to singles and there was significant association between lifetime prevalence of LBP and marital status $(\mathrm{P}=0.000)$. Based on their body mass index (BMI), the participants were divided into obese and non-obese groups. Point as well as lifetime prevalence $(46.2,76.9)$ was high among obese office workers and there was significant association between $\mathrm{BMI}$ and point prevalence of $\operatorname{LBP}(\mathrm{P}=0.041$, 0.254). Prevalence of LBP was higher among low educated workers as compared to high educated workers and there was an association between education level and point prevalence of LBP $(\mathrm{P}=0.002)$. Significant difference of point LBP prevalence was noted between nonexercising (37.1\%) and exercising (21.4\%) groups. The office workers with exercising habit were classified into once/week, twice/week, thrice/week and more than thrice a week categories. The percentage of both prevalence (point and lifetime) decreased with the increase of exercise sessions. Descriptive analysis for sleep disturbance was calculated and differences between no sleep disturbance, 1-2 time/week sleep disturbances, 3 time/week sleep disturbances, and sleep disturbance for whole week showed that increase in the number of sleep disturbances is directly proportional to the prevalence of LBP and there was strong association between point prevalence of LBP with sleep disturbance $(\mathrm{P}=0.000)$. Majority of the office workers were non-smokers and there was strong association between lifetime prevalence of LBP and smoking.

Work ergonomic characteristics such as work experience, daily sitting time, daily computer use, body position in sitting, forward bending, distance of computer screen from worker's body, adjustable back support and job satisfaction level displayed significant values for both point and lifetime prevalence as shown in Table 1 . Bivariate logistic regression analysis was used to predict the risk factors of LBP with respect to predisposing factors that its values are shown in Table 2.

\section{Discussion}

The main purpose of this study was to find out the point and lifetime prevalence of LBP among the office workers of KEMU Lahore, Pakistan. This study had also examined the predisposing factors causing LBP among the office workers of this university. This is the first survey conducted in a Pakistani university to find out the prevalence of LBP. Results of this study have shown high prevalence of point as well as lifetime LBP among office workers.

Among the individual risk factors, female office workers showed high prevalence of LBP but no significant differences were detected between gender and prevalence of LBP. Most previous studies had also shown the high prevalence of LBP among females [19]. According to our results, point and lifetime prevalence of LBP was low among single people with significant association between marital status and LBP, which was similar with the results found by other authors [20]. The results of this study confirm that an increase in BMI increases the percentage of LBP prevalence among the office workers which are similar to the results of other studies [21, 22].

Previous studies have reported that exercising habits were not significant predictors of LBP prevalence [23], but the current study has demonstrated a positive association and reported that LBP decreased with the increase of exercise sessions in a week. Education level and sleep disturbance are also significant and common factors associated with LBP prevalence. Leboeuf-Yde concluded that smoking should be considered a weak risk factor and not a cause of LBP [24]; however, this study like another study suggested that smoking is positively associated with future LBP (OR 1.38-6.38) [25].

Work related and ergonomic factors also showed significant differences. LBP is associated with increasing 
working years as shown in the results, while another study showed that LBP was least among those office workers who had work experience for less than 10 years [26]. Sitting and standing time were found to be significantly associated with point prevalence of LBP. According to results, prevalence of LBP rises with increasing the sitting time which is consistent to other study results [9].

The distance from the computer screen was not a significant predictor in this research but it might be a factor for body adjustment to a non-neutral position which stresses the lumbar region and produces pain. The forward bent body position increases spinal loading and contributes to LBP, but according to a systematic review, occupational bending or twisting is not likely the cause of LBP in workers and the association was often rated as weak or moderate [27]. Adjustable back support is associated with decreased rates of LBP in this research but not significant according to other studies [28].

Job satisfaction level was assessed by using a 4-point Likert-type scale, which showed low prevalence of LBP among satisfied office workers but was only significantly associated with life time prevalence of LBP. It was reported that low job satisfaction was associated with an increased risk for the occurrence of LBP [29]. Results from the present study are in agreement with the findings of Mohseni-Bandpei [21] and Smith [30] studies concerning the effect of job satisfaction on LBP.

This study had also some limitations as it was the first to examine the prevalence and risk factors of LBP among

Table 1. Demographic, personal, work ergonomic, and psychosocial characteristics of KEMU office workers.

\begin{tabular}{|c|c|c|c|c|c|c|c|}
\hline & & \multicolumn{2}{|c|}{ Sample Size } & \multicolumn{2}{|c|}{ Point Prevalence of LBP } & \multicolumn{2}{|c|}{ Lifetime Prevalence of LBP } \\
\hline & & No. & $\%$ & $\%$ POS & $\mathbf{P}$ & $\%$ POS & $\mathbf{P}$ \\
\hline \multirow{3}{*}{ Gender } & Male & 118 & 47.2 & 25.4 & & 66.9 & \\
\hline & & & & & 0.135 & & 0.277 \\
\hline & Female & 132 & 52.8 & 32.6 & & 71.2 & \\
\hline \multirow{3}{*}{ Marital status } & Single & 85 & 34 & 20 & & 54.1 & \\
\hline & & & & & 0.015 & & 0.000 \\
\hline & Married & 165 & 66 & 33.9 & & 77.0 & \\
\hline \multirow{3}{*}{ Body Mass Index (BMI) } & Non-obese & 224 & 89.6 & 27.2 & & 68.3 & \\
\hline & & & & & 0.041 & & 0.254 \\
\hline & Obese & 26 & 10.4 & 46.2 & & 76.9 & \\
\hline \multirow{3}{*}{ Education level } & Intermediate & 45 & 18 & 51.1 & & 75.6 & \\
\hline & Graduate & 120 & 48 & 23.3 & 0.002 & 61.7 & 0.046 \\
\hline & $\begin{array}{l}\text { Master or } \\
\text { PhD }\end{array}$ & 85 & 34 & 25.9 & & 76.5 & \\
\hline \multirow{3}{*}{ Exercise } & No & 124 & 49.6 & 37.1 & & 75.8 & \\
\hline & & & & & 0.005 & & 0.017 \\
\hline & Yes & 126 & 50.4 & 21.4 & & 62.7 & \\
\hline \multirow{5}{*}{$\begin{array}{l}\text { Number of exercise (Ses- } \\
\text { sions/week) }\end{array}$} & 1 & 18 & 7.2 & 38.9 & & 77.8 & \\
\hline & 2 & 34 & 13.6 & 26.5 & & 64.7 & \\
\hline & & & & & 0.017 & & 0.099 \\
\hline & 3 & 44 & 17.6 & 15.9 & & 59.1 & \\
\hline & $>3$ & 30 & 12 & 13.3 & & 56.7 & \\
\hline \multirow{5}{*}{$\begin{array}{l}\text { Sleep disturbance (Times/ } \\
\text { week) }\end{array}$} & $\begin{array}{l}\text { No distur- } \\
\text { bance }\end{array}$ & 159 & 63.6 & 19.5 & & 64.8 & \\
\hline & $1-2$ & 47 & 18.8 & 38.3 & & 72.3 & \\
\hline & & & & & 0.000 & & 0.173 \\
\hline & 3 & 12 & 4.8 & 41.7 & & 83.3 & \\
\hline & No sleep & 32 & 12.8 & 59.4 & & 81.2 & \\
\hline
\end{tabular}




\begin{tabular}{|c|c|c|c|c|c|c|c|}
\hline & & \multicolumn{2}{|c|}{ Sample Size } & \multicolumn{2}{|c|}{ Point Prevalence of LBP } & \multicolumn{2}{|c|}{ Lifetime Prevalence of LB } \\
\hline & & No. & $\%$ & $\%$ POS & $\mathbf{P}$ & $\%$ POS & $\mathbf{P}$ \\
\hline \multirow{3}{*}{ Smoking habit } & Non-smokers & 222 & 88.8 & 28.8 & & 66.7 & \\
\hline & & & & & 0.434 & & 0.009 \\
\hline & Smokers & 28 & 11.2 & 32.1 & & 89.3 & \\
\hline \multirow{3}{*}{ Work experience $(y)$} & $\leq 10$ & 122 & 48.8 & 16.4 & & 56.6 & \\
\hline & $10-19$ & 55 & 22.0 & 41.8 & 0.000 & 83.6 & 0.000 \\
\hline & $\geq 20$ & 73 & 29.2 & 41.1 & & 79.5 & \\
\hline \multirow{3}{*}{ Sitting time $(\mathrm{h})$} & $\leq 4$ & 76 & 30.4 & 17.1 & & 60.5 & \\
\hline & $4-8$ & 133 & 53.2 & 29.3 & 0.001 & 72.2 & 0.134 \\
\hline & $\geq 8$ & 41 & 16.4 & 51.2 & & 75.6 & \\
\hline \multirow{5}{*}{ Standing time per day (h) } & $1-2$ & 130 & 52.0 & 37.7 & & 70.8 & \\
\hline & $2-4$ & 84 & 33.6 & 16.7 & & 69.0 & \\
\hline & & & & & 0.010 & & 0.240 \\
\hline & $4-6$ & 21 & 8.4 & 23.8 & & 76.2 & \\
\hline & $>6$ & 15 & 6.0 & 33.3 & & 46.7 & \\
\hline \multirow{3}{*}{ Forward bending } & No & 132 & 52.80 & 22.7 & & 65.20 & \\
\hline & & & & & 0.012 & & 0.092 \\
\hline & Yes & 118 & 47.20 & 36.4 & & 73.70 & \\
\hline \multirow{3}{*}{ Back support in chair } & No & 143 & 57.2 & 30.1 & & 72.00 & \\
\hline & & & & & 0.418 & & 0.163 \\
\hline & Yes & 107 & 42.8 & 28.0 & & 65.40 & \\
\hline \multirow{3}{*}{ Back adjustment } & No & 65 & 26.00 & 24.60 & & 67.70 & \\
\hline & & & & & 0.589 & & 0.437 \\
\hline & Yes & 42 & 16.80 & 33.30 & & 61.90 & \\
\hline \multirow{2}{*}{ Usual body position } & $\begin{array}{l}\text { No forward } \\
\text { bending }\end{array}$ & 127 & 50.8 & 18.90 & & 60.60 & \\
\hline & Bending $>2 h$ & 123 & 49.2 & 39.80 & & 78.00 & \\
\hline \multirow{3}{*}{ Daily Computer use (h) } & $\leq 3$ & 119 & 47.6 & 19.30 & & 61.3 & \\
\hline & $3-6$ & 52 & 20.8 & 32.70 & 0.003 & 67.3 & 0.007 \\
\hline & $\geq 6$ & 79 & 31.6 & 41.80 & & 82.3 & \\
\hline \multirow{3}{*}{$\begin{array}{l}\text { Body distance from com- } \\
\text { puter screen }(\mathrm{cm})\end{array}$} & $\leq 50$ & 77 & 30.80 & 32.50 & & 67.5 & \\
\hline & $50-100$ & 109 & 43.60 & 29.40 & 0.802 & 65.1 & 0.390 \\
\hline & $\geq 100$ & 27 & 10.80 & 29.62 & & 80.0 & \\
\hline \multirow{5}{*}{ Satisfaction level of job } & None & 15 & 6.00 & 46.70 & & 80.00 & \\
\hline & Little & 26 & 10.40 & 42.30 & & 80.80 & \\
\hline & & & & & 0.155 & & 0.267 \\
\hline & Enough & 131 & 52.40 & 26.70 & & 69.50 & \\
\hline & Very much & 78 & 31.20 & 25.60 & & 62.80 & \\
\hline
\end{tabular}


Table 2. Significant risk factors as predictors for LBP prevalence in KEMU office workers.

\begin{tabular}{|c|c|c|c|c|}
\hline & Factors & OR (Adjusted) & $95 \% \mathrm{Cl}$ & $\mathbf{P}$ \\
\hline Marital status & $\begin{array}{c}\text { Single (reference) } \\
\text { Married }\end{array}$ & 1.40 & $0.61-3.20$ & 0.430 \\
\hline Sleep disturbance & $\begin{array}{c}\text { No sleep disturbance (reference) } \\
1-2 \text { times } \\
3 \text { times } \\
\text { No sleep }\end{array}$ & $\begin{array}{l}2.66 \\
2.39 \\
4.22\end{array}$ & $\begin{array}{c}1.16-6.06 \\
0.52-11.06 \\
1.66-10.73\end{array}$ & $\begin{array}{l}0.020 \\
0.264 \\
0.002\end{array}$ \\
\hline Standing hours & $\begin{array}{c}1-2 \text { (Reference) } \\
>2\end{array}$ & 0.58 & $0.27-1.23$ & 0.155 \\
\hline Education level & $\begin{array}{c}\text { Master or PhD (reference) } \\
\text { Intermediate } \\
\text { Graduate }\end{array}$ & $\begin{array}{l}1.92 \\
1.02\end{array}$ & $\begin{array}{l}0.70-5.32 \\
0.46-2.25\end{array}$ & $\begin{array}{l}0.207 \\
0.970\end{array}$ \\
\hline Computer using time $(\mathrm{h})$ & $\begin{array}{c}\geq 6 \text { (Reference) } \\
\leq 3 \\
3-6\end{array}$ & $\begin{array}{l}0.76 \\
1.16\end{array}$ & $\begin{array}{l}0.30-1.92 \\
0.43-3.15\end{array}$ & $\begin{array}{l}0.558 \\
0.766\end{array}$ \\
\hline Work experience (y) & $\begin{array}{c}\geq 20 \text { y (Reference) } \\
\leq 10 \\
10-19\end{array}$ & $\begin{array}{l}0.45 \\
1.22\end{array}$ & $\begin{array}{l}0.18-1.16 \\
0.48-3.06\end{array}$ & $\begin{array}{l}0.101 \\
0.675\end{array}$ \\
\hline Sitting hours (h) & $\begin{array}{l}\leq 4 \text { (Reference) } \\
\quad 4-8 \\
\geq 8\end{array}$ & $\begin{array}{l}1.52 \\
1.89\end{array}$ & $\begin{array}{l}0.62-3.70 \\
0.54-6.65\end{array}$ & $\begin{array}{l}0.359 \\
0.320\end{array}$ \\
\hline Exercise & $\begin{array}{c}\text { No } \\
\text { Yes (Reference) }\end{array}$ & 2.32 & $1.17-4.60$ & 0.016 \\
\hline Usual body position & $\begin{array}{l}\text { No Forward bending (reference) } \\
\text { Forward bending } \geq 2 \mathrm{~h}\end{array}$ & 2.25 & $1.07-4.72$ & 0.032 \\
\hline Forward bending & $\begin{array}{l}\text { No (reference) } \\
\text { Yes }\end{array}$ & 2.08 & $1.02-4.24$ & 0.043 \\
\hline BMI & $\begin{array}{c}\text { Non-obese (reference) } \\
\text { Obese }\end{array}$ & 2.40 & $0.80-7.22$ & 0.118 \\
\hline
\end{tabular}

university office workers in Pakistan. The office workers were not familiar with such studies, so the research team had to convince them to complete the questionnaire forms and few office workers were not paying appropriate attention. The type of chairs in different departments was not similar, so this fact may also affect the results of the study. The study design was cross-sectional, so precau- tionary measures should be taken while interpreting the results because that might express only association and not causation between the risk factors and prevalence of LBP. Also data regarding smoking and exercise showed no relation between frequency and type of exercise. Job satisfaction was a multi-dimensional concept, so data did not clarify the reasons behind the job dissatisfaction. 
This study concluded that point as well as lifetime prevalence of LBP was high among KEMU office workers and lack of exercise, sleep disturbance, smoking, more work experience, long sitting, forward bending, body position, distance from computer screen, and low job satisfaction were the main predisposing factors causing LBP. Educational programs are much needed to create awareness among the office workers about above mentioned risk factors of LBP.

\section{Acknowledgements}

We are grateful to the authorities of the King Edward Medical University, Lahore, Pakistan for their kind permission to conduct the survey and also Tehran University of Medical Sciences Iran for funding this research.

\section{Conflict of Interest}

The authors declared no conflicts of interest.

\section{References}

[1] Koes B, Van Tulder M. Acute low back pain. American family physician. 2006; 74(5):803-5. PMID: 16970025

[2] Spyropoulos P, Papathanasiou G, Georgoudis G, Chronopoulos E, Koutis H, Koumoutsou F. Prevalence of low back pain in Greek public office workers. Pain Physician. 2007; 10(5):651. PMID: 17876361

[3] Hoy D, Bain C, Williams G, March L, Brooks P, Blyth F, et al. A systematic review of the global prevalence of low back pain. Arthritis \& Rheumatism. 2012; 64(6):2028-37. doi: $10.1002 /$ art.34347

[4] Walker BF. The prevalence of low back pain: A systematic review of the literature from 1966 to 1998. Journal of Spinal Disorders. 2000; 13(3):205-17. doi: 10.1097/00002517200006000-00003

[5] Macedo AC, Trindade CS, Brito AP, Socorro Dantas M. On the effects of a workplace fitness program upon pain perception: A case study encompassing office workers in a Portuguese context. Journal of Occupational Rehabilitation. 2010; 21(2):228-33. doi: 10.1007/s10926-010-9264-2

[6] Roelen CA, Koopmans PC, Groothoff JW. Subjective health complaints in relation to sickness absence. Work. 2010; 37(1):15-21

[7] Burdorf A, Naaktgeboren B, de Groot HC. Occupational risk factors for low back pain among sedentary workers. Journal of Occupational and Environmental Medicine. 1993; 35(12):1213-20. PMID: 8113925

[8] Verbeek JH, Van der Beek AJ. Psychosocial factors at work and back pain: A prospective study in office workers. In- ternational Journal of Occupational Medicine and Environmental Health. 1998; 12(1):29-39.

[9] Omokhodion FO. Risk factors for low back pain among office workers in Ibadan, Southwest Nigeria. Occupational Medicine. 2003; 53(4):287-9. doi: 10.1093/occmed/kqg063

[10] Ortiz-Hernández L, Tamez-González S, Martinez-Alcántara S, Méndez-Ramirez I. Computer use increases the risk of musculoskeletal disorders among newspaper office workers. Archives of Medical Research. 2003; 34(4):331-42. doi: 10.1016/s0188-4409(03)00053-5

[11] Mörl F, Bradl I. Lumbar posture and muscular activity while sitting during office work. Journal of Electromyography and Kinesiology. 2013; 23(2):362-8. doi: 10.1016/j.jelekin.2012.10.002

[12] Del Pozo-Cruz B, Gusi N, Adsuar JC, del Pozo-Cruz J, Parraca JA, Hernandez-Mocholí M. Musculoskeletal fitness and health-related quality of life characteristics among sedentary office workers affected by sub-acute, non-specific low back pain: A cross-sectional study. Physiotherapy. 2013; 99(3):194-200. doi: 10.1016/j.physio.2012.06.006

[13] Alipour A, Ghaffari M, Shariati B, Jensen I, Vingard E. Occupational neck and shoulder pain among automobile manufacturing workers in Iran. American Journal of Industrial Medicine. 2008; 51(5):372-9. doi: 10.1002/ajim.20562

[14] Choobineh A, Tabatabaei SH, Mokhtarzadeh A, Salehi M. Musculoskeletal problems among workers of an Iranian rubber factory. Journal of Occupational Health. 2007; 49(5):418-23. doi: 10.1539/joh.49.418

[15] Choobineh A, Tosian R, Alhamdi Z, Davarzanie M. Ergonomic intervention in carpet mending operation. Applied Ergonomics. 2004; 35(5):493-6. doi: 10.1016/j.apergo.2004.01.008

[16] Choobineh A, Movahed M, Tabatabaie SH, Kumashiro M. Perceived demands and musculoskeletal disorders in operating room nurses of Shiraz city hospitals. Industrial Health. 2010; 48(1):74-84. doi: 10.2486/indhealth.48.74

[17] Davidson M, Keating J. Oswestry Disability Questionnaire (ODQ). Australian Journal of Physiotherapy. 2005; 51(4):270. doi: 10.1016/s0004-9514(05)70016-7

[18] Chansirinukor W, Maher CG, Latimer J, Hush J. Comparison of the functional rating index and the 18-item Roland-morris disability questionnaire: Responsiveness and reliability. Spine. 2005; 30(1):141-5. doi: 10.1097/00007632200501010-00023

[19] Ihlebæk C, Hansson T, Lærum E, Brage S, Eriksen H, Holm $\mathrm{S}$, et al. Prevalence of low back pain and sickness absence: A "borderline" study in Norway and Sweden. Scandinavian Journal of Public Health. 2006; 34(5):555-8. doi: 10.1080/14034940600552051

[20] Biglarian A, Seifi B, Bakhshi E, Mohammad K, Rahgozar M, Karimlou M, et al. Low back pain prevalence and associated factors in Iranian population: Findings from the national health survey. Pain Research and Treatment. 2012; 2012:1-5. doi: $10.1155 / 2012 / 653060$

[21] Mohseni-Bandpei MA, Fakhri M, Bargheri-Nesami M, Ahmad-Shirvani M, Khalilian AR, Shayesteh-Azar M. Occupational back pain in Iranian nurses: An epidemiological 
study. British Journal of Nursing. 2006; 15(17):914-7. doi: 10.12968/bjon.2006.15.17.21904

[22] Hu HY, Chen L, Wu CY, Chou YJ, Chen RC, Huang N. Associations among low back pain, income, and body mass index in Taiwan. Spine. 2013; 13(11):1521-6. doi: 10.1016/j. spinee.2013.06.049

[23] Riihimäki H, Viikari-Juntura E, Moneta G, Kuha J, Videman $\mathrm{T}$, Tola S. Incidence of sciatic pain among men in machine operating, dynamic physical work, and sedentary work. Spine. 1994; 19(2):138-42. doi: 10.1097/00007632-19940100100003

[24] Leboeuf-Yde C. Smoking and low back pain. Spine. 1999; 24(14):1463-70. doi: 10.1097/00007632-199907150-00012

[25] Hestbaek L, Leboeuf-Yde C, Kyvik KO. Are lifestyle-factors in adolescence predictors for adult low back pain? A crosssectional and prospective study of young twins. BMC Musculoskeletal Disorders. 2006; 7(1):27. doi: 10.1186/1471-24747-27

[26] Janwantanakul P, Pensri P, Moolkay P, Jiamjarasrangsi W. Development of a risk score for low back pain in office workers - a cross-sectional study. BMC Musculoskeletal Disorders. 2011; 12:23. doi: 10.1186/1471-2474-12-23

[27] Wai EK, Roffey DM, Bishop P, Kwon BK, Dagenais S. Causal assessment of occupational bending or twisting and low back pain: Results of a systematic review. Spine. 2010; 10(1):76-88. doi: 10.1016/j.spinee.2009.06.005

[28] Makhsous M, Lin F, Hendrix RW, Hepler M, Zhang LQ. Sitting with adjustable ischial and back supports: Biomechanical changes. Spine. 2003; 28(11):1113-21. doi: 10.1097/01. brs.0000068243.63203.a8

[29] Van Poppel MMN, Koes WB, Devillé W, Smid T, Bouter ML. Risk factors for back pain incidence in industry: A prospective study. Pain. 1998; 77(1):81-6. doi: 10.1016/s03043959(98)00085-2

[30] Smith DR, Mihashi M, Adachi Y, Koga H, Ishitake T. A detailed analysis of musculoskeletal disorder risk factors among Japanese nurses. Journal of Safety Research. 2006; 37(2):195-200. doi: 10.1016/j.jsr.2006.01.004 